\title{
"Customerized" innovation through the emergence of a mutually adaptive and learning environment
}

\author{
SASKIA J.M. HARKEMA* AND WALTER BAETS
}

\begin{abstract}
This paper describes an experimental approach to model an innovation process on the basis of principles and concepts of complexity theory and its possible implications on the outcome of the innovation process. It is part of ongoing research carried out at the University of Nyenrode in the Netherlands, at the Nyenrode Institute of Virtual Education and Knowledge Management. In this paper the intricate and complex relation underlying the process of new product development and customer response, is the focus of attention. This relation is primarily defined as a process of knowledge management and mutual learning (Baets, 1998). In addition innovation is defined as a process of "manageable chaos" (adapted from Quinn, 1985). This means that innovation is conceptualized as a process of interaction and subsequent knowledge flows between people that are organized in a network and form a complex system. In the sixties Simon, one of the founders of complexity theory, defined a complex system as one made up of many parts that have many intricate interactions. An alternative will be brought forward to model innovation processes. Instead of defining innovation success in terms of organizational characteristics or factors linked to the success rate of a product innovation; the latter will be modeled as the outcome of interaction among a variety of agents that pursue strategies in a co-evolutionary process with each other.
\end{abstract}

Classification Codes: M21.

\section{Introduction}

"Customerized" innovation is defined as innovation that emerges out of interaction between organizational agents (i.e. employees, managers, members of the Board) and customers. The driving motor is sharing and exchanging of knowledge, explicit and tacit, in a mutually adaptive and learning environment. This environment does not specifically refer to an I.T. system, but to a network of people that interact with each other. In this paper an overview is given of on-going research into the intricate relation between organizations and customers involved in a product innovation process. This relation will be highlighted from different perspectives.

\footnotetext{
* University of Nyenrode, Nyenrode Institute of Knowledge Management and Virtual Education (NOTION) 3621 BG Breukelen, The Netherlands. E-mail: s.harkema@nyenrode.nl

Keywords: Customerized innovation, knowledge management, complexity, learning.
} 
In first instance, complexity theory will be used as a frame of reference to analyze its implications on traditional innovation concepts and processes, and the effect of the latter on innovation performance. In the sixties, Simon, one of the founders of complexity theory, defined complexity as a system made up of a large number of parts that have many intricate interactions. Assumptions underlying complex adaptive-system modeling will be used to explain how the intricate and complex interactions of an innovation trajectory could be modeled. In general these models are characterized by four elements (Lewin, 1998; Anderson, 1999):

1. Agents with cognitive schemata.

2. The way agents are connected to each other and the interaction patterns resulting from that interaction.

3. The way agents co-evolve with each other in a process of continuous adaptation "to the edge of chaos". This notion refers to the way living systems operate at their most efficient level in the transition phase between stability and disorder poised at "the edge of chaos" (Kauffman, 1993).

4. The way the system evolves under the influence of changing circumstances (different agents, different contextual aspects).

Secondly from a knowledge-management perspective, whereby Quinn's (1992) concept of the "intelligent organization" will be used to understand the general nature of knowledge-based organizations as opposed to traditional organizations. He has developed the concept of the "intelligent" organization, which refers to the ability of companies to manage intellectual capital, i.e. knowledge, and transform it into valueadded offerings.

Innovation is the basis for organizational continuity; without innovation eventually an organization has no future. Innovation is at the same time one of the most elusive and difficult processes to manage. Taking into consideration that on average 6 out of 10 innovations fail (Hultink, 1997) it becomes crystal clear that the innovation capabilities of any enterprise are crucial for its survival. Innovation processes within companies are mostly organized as a series of activities going through different stages; idea, concept, feasibility, development and launch (Cooper, 1987; Utterback, 1996; Christensen 1997).

With an existing multinational of fast moving consumer goods (fmcg) as a reference point, this article will elaborate on the intricate and complex relation between product innovation and customer response, and its effect on new product developments. Most companies understand that their product creation process is a critical success factor. The company in this case has opted for structuring the new product development process within a funnel approach, which is expected to help increase the rate of new product successes in the market place. A funneled approach structures product development activities in phases from ideas through to market launch. The first phase, the idea phase, the "wide" mouth of the funnel contains many ideas that eventually lead to new concepts suitable for development. Every phase or stage is designed so as to reduce uncertainty as much as possible. Via gate-reviews after every stage a go or no-go decision has to be taken. The aim is to thus be able to "manage" the risk and complexity involved as best as possible. This specific company is confronted with the fact that innovation as such is growing in importance, and that (a) speed, (b) internal and external communication, 
(c) efficiency, (d) quality, and (e) knowledge sharing are key factors of success. It has set itself as objective to become a learning and innovative company.

The argument made in this article is that innovation is "manageable chaos" (adapted from Quinn, 1985) and the idea will be explored whether complexity theory offers a better framework than traditional ways of designing and assessing product innovations. What is new about this perspective? Science has until now been founded on the assumption that there is a causal relation between events. Causality supposes that a certain change in one variable will lead to a predictable outcome in another variable, which can be forecasted. Complexity theory argues that relationships are seldom linear, and that it is important to understand that it is exactly these non-linear relations that work as a stabilizing force in a dynamic chaotic system.

Complexity can imply both order and chaos, whereby chaos not necessarily implies disorder. On the contrary order is something that emerges out of the interaction between the elements or agents forming a network. The consequence is that order cannot be anticipated or forecasted; the only thing that a scientist can do is have a clear understanding and insight in the interaction between the agents within a network and be aware of the fact that purpose will emerge as a self-organizing principle.

Complexity theory has not yet been applied to a large extent to business processes. As mentioned earlier product innovations are one of the most difficult processes to manage in an enterprise. It is therefore of great importance to understand the mechanisms that govern and underlie innovation processes and define alternatives that can possibly lead to an improvement of the rate of success. Ultimately the rate of success is determined by the customer who will make a decision to buy or not on the basis of the perception and knowledge of what a company has to offer. And the extent to which the latter is willing and able to integrate customer knowledge into the organizational business process underlying product innovations.

In this article the contours of an approach of an innovation process will be defined, whereby the interaction between an organization and customers, and its effect on organizational innovation, will be viewed as an emergent process ruled by the principles of complexity theory.

In the course of the article a number of aspects will be clarified:

1. The implications of complexity theory on our perception of social reality.

2. On a more general level: how new economic concepts are affecting the business landscape.

3. Changing views on innovation: from a technology or R\&D driven activity to a more people (employees and customers) centered activity of knowledge sharing.

4. Ultimately, the effect of the application of concept of complex adaptive on innovation processes and its possible effects.

\section{Social reality and complexity}

\subsection{Characteristics of complex systems}

Complexity is a term much used and heard nowadays, though in its business application it is still in its "early adopters" phase. The Latin "complexus" stems from the Greek "pleko" which means to "twine or to plait". Complex systems are woven up of many 
parts, and the science of complexity is essentially a quest to try to understand the patterns of the woven fabric.

Complexity theory advocates that systems should be regarded as a whole, rejecting the traditional emphasis on simplification and reductionism. Complexity theory grew out of observing reality and more in particular weather forecasting. Scientists developed the concept from working with mathematical models for perfect weather forecasting. Their conclusion was that there is repetitiveness in the system in the medium term, but it is impossible to make exact predictions about what will happen on the long term. In contrast to earlier scientific assumptions, complexity theory pinpoints the source of social order in the non-linear dynamics of a system. In the past nearly all-scientific models assumed that the most optimal situation was a stable system and that stability was to be pursued. In reality chaos or a dynamic system seemed to be a more appropriate and truthful image of reality. In a dynamic system there is unpredictability within boundaries. The dynamism lays in the fact that the output is not known beforehand, whatever the input, and the feedback loops are unpredictable as well.

Organizational success has until now been mostly defined in financial terms (profit growth, ROI, RONA). The difficulty is that these parameters ignore the fact that the outcome of a process is a function of the complex array of factors underlying these processes and their interconnection. The most pregnant difference between a reductionist view on reality and an interconnected view, is the difference between managing in a mechanistic way characteristic of the industrial age, and managing complex adaptive systems in the knowledge age. Complexity theory, and more in particular complex adaptive systems theory, offers interesting concepts and tools to understand and analyze organizational behavior. The essence of a complex adaptive system is that it is a system of semi-independent units that interact randomly with each other and in doing so influence each other's behavior. Organizations emerge from this intricate web of human relationships and interactions, which in their turn are continuously fed back into the organization and affect the way things are organized, and the way people give meaning to reality.

\subsection{Tools to study complex systems}

The dynamics of complex systems can be analyzed with the help of mathematical modeling and computer simulations. A typical simulation consists of a number of interacting agents whose interaction patterns are defined by a set of rules they follow.

In very broad lines it can be said that modeling complex behavior can be done in two ways:

1. Cybernetics, general systems theory, catastrophe theory and chaos theory; which all address deterministic dynamical systems.

2. Complex adaptive systems theory, which models complex behavior as a set of interacting agents in a network, and examines the regularity emerging from the interaction patterns of people connected with each other ${ }^{1}$.

\footnotetext{
${ }^{1}$ There is a special issue of Accounting Management \& Information Technology (1998) which deals with modeling of complex adaptive systems.
} 
Modeling can be done from different perspectives. Generally speaking two streams can be distinguished in computational modeling. In so-called traditional artificial intelligence (AI) an individual agent's mental processes and behavior are modeled. The focus is on the cognitive processes. In artificial life and computational organizational theory, the system is the focus of attention. Another alternative, based on the constructivist approach, assumes that agents are socially embedded in a network of agents and modeling is done of that agent as part of the total system of agents and their interactions. Complex adaptive system modeling departs from this perspective.

There are several types of computer models that have been used to study complex adaptive systems, amongst which cellular automata, neural networks and genetic algorithms. These are so-called "off-the shelf" algorithms. According to Edmonds (2000) their drawback is that they lack a justification of appropriateness or a modification to make them appropriate to model a certain social phenomenon.

An alternative or addition to modeling is to simulate behavior of complex adaptive systems. The Santa Fe Institute has developed a simulation tool, SWARM, which can simulate the behavior emerging from interaction in complex adaptive systems and may be used to model new product innovation processes as a complex adaptive system (www.santafe.edu/projects/swarm). SWARM offers the opportunity of multi-agent simulation of complex systems ${ }^{2}$. As such it opens up possibilities to simulate an innovation process as a CAS.

Innovation will be defined as a complex adaptive system for the reasons mentioned earlier, and in addition because it is: (a) multidisciplinary and multi-functional, (b) it involves cross-border and cross departmental interactions, (c) it spans over a long period of time, (d) it involves vertical and horizontal communication flows, (e) it depends largely on people and the knowledge they possess and their decision-making. The path proposed in this article is not to model on the basis of fixed a priori principles, but follow a more descriptive approach as advocated by Edmonds (2000). Observation and description precedes modeling in this case. In the course of this research, it will become clear what the consequences will be of this method, for the development of a "complex adaptive model of innovation".

It seems obvious that complexity theory has affected our perception of the world in an all-encompassing and penetrating way: the next chapters will deal with changing views on traditional economic theory, and organizational theories and modeling.

\section{Economic theory and complexity}

The modern theory of economics is based on Walras, Marshall and Jevons. In the midnineteenth century, energy physicists developed what may well be one of the most prevailing metaphors of our time: that of closed equilibrium systems. This is the core metaphor of traditional economic theory and much of management thinking. The sequence of equilibrium-change a variable-new equilibrium forms the basis of traditional economic theory and most business strategy. In a typical strategy analysis, a company will make an

\footnotetext{
${ }^{2}$ See also Luna and Stefanson (2000).
} 
assessment of its current position, consider the changes that might occur and develop a point of view on how the industry is likely to change and affect the business strategy. This approach is based on three assumptions: (1) that the industry structure is known, (2) that the law of diminishing returns applies and (3) that firms are perfectly rational. Marshall's equilibrium model was a reasonable approximation to the agricultural and manufacturing economy, but appears not to hold in a dynamic service and knowledge based economy.

In traditional micro-economic theory the relationship between a firm and a buyer is essentially based on economic value. The price-mechanism is a means of organizing economic activity, by coordinating the decisions of consumers, producers and owners of productive resources. In an economic system, the price-mechanism is the instrument by which is determined what to produce in what quantity, how (scarce) resources are allocated, and finally whom these products or services are meant for. To a buyer price is the value placed on the good to be exchanged, either to satisfy a utility or a need. To a seller price is the element that influences the generation of total revenues. It is therefore in the interest of the seller to set the price at such a level that he will gain the most revenues while at the same time satisfying the buyer. Normally speaking price and demand are inversely related, the higher the price the lower the demand.

The traditional economic paradigm explains behavior and performance with the aid of models that measure input (supply) and output variables (demand). In the last ten years variables to measure performance have become more "organic", as a result of the growing awareness of the complexity of reality. Organizations are regarded as open systems with continuous interaction taking place between the organization and its environment. This environment is subject to constant changes that organizations have to cope with, and this makes it necessary to harness change instead of trying to control it.

In the nineties concepts of complexity started to affect traditional economic theory (Quinn, 1992; Arthur, 1994; Boisot, 1995; Haeckel, 1999). According to Haeckel (1999) productivity in the industrial economy was achieved through knowledge applied to natural resources, machines and labor. While nowadays productivity improvements rely on application of knowledge to knowledge. Arthur (1993) reflects on the fact that looking back in time, life seemed to be less complex and that raises the question whether there are general principles causing complexity. He argues that in parts of the economy that are resource-based (agriculture, mining, bulk-goods production) conventional economics hold. The parts of economics that are knowledge based are however largely subject to increasing returns. The information and knowledge economy work differently given that economic properties of information differ from those of material resources. Traditional capital assets have maximum value before they are used. Until used, however, information has no value at all. Land, labor, capital and energy are appropriable, that is, once given away they no longer belong to the giver. Moreover their value generally increases, as they become scarcer. These economic laws do not govern information. Those who give information to others still have it and the value of knowledge tends to increase rather than decrease with sharing and use, i.e. volume. In addition Arthur (1994) developed the idea of positive feedbacks in economics. Technologies typically improve as more people adopt them and firms gain experience that guides further development. This link is a positive feedback loop. The more people adopt a technology, the more it 
will improve, the more attractive it will become for further adoption. Arthur is excited about the prospect of these positive feedbacks because as a consequence traditional assumptions underlying traditional economic theory are slowly being replaced. The economy becomes a complex, non-deterministic, organic and evolutionary process ${ }^{3}$.

\section{Organizational complexity and innovation}

In line with traditional economic theories of the firm, organizational theories have been formulated and developed. Organizations are traditionally viewed as rational entities where land, labor and capital are primary production sources geared towards meeting market demand. As traditional sources of economic activity and advantage are being replaced by less tangible ones, traditional theories of the firm conversely become less suitable as a tool to understand and analyze organizations and the environment wherein they operate.

In broad lines three approaches to management and organizations can be distinguished: (1) a mechanistic approach, (2) an entrepreneurial organic approach, and (3) a dynamic approach. The mechanistic approach regards an organization as a mindless system with no purpose of its own. People are bound together by hierarchy and clear-cut goals. Organic approaches view organizations as human beings with a purpose of their own. The main aim is to achieve a fit between customer requirements and internal capabilities. The way in which the organization creates the environment of which it is an intrinsic part, is not taken into account. A rational mechanistic and an organic model for a long period were the predominant organization paradigms. This is reflected in the popularity of strategic fit and strategic planning that prevailed in the fifties and sixties. The environment was consequently defined in terms of procedures, checklists, and factors to be controlled.

In the seventies a resource-based theory of the firm was defined by Pfeffer and Salancik (1978) emphasizing the internal aspects of a firm in addition to intangible aspects like market knowledge, organizational culture and management skills. In that same period Porter (1980) developed his five-forces model that added an element of external justification to prior models. Porter's work assumes that economic considerations are primary in determining organizational performance. His framework is defined in terms of five competitive forces that explain profitability within an industry and a firm. All these models regarded the economy and organizations as a large Newtonian system with a unique equilibrium point that could be achieved with the right input.

Also in the seventies Weick (1979) questioned the epistemological grounding of prior theories, which made a clear, and, in his view, artificial distinction between subject and object. He developed the concept of the "enacted environment" to explain that people construct meaning and reality in creating the environment to which they in turn respond.

\footnotetext{
${ }^{3}$ Arthur argues that an economy of complexity is an economy created by the minds of its agents. Subject and object cannot be separated, the economy emerges from subjective beliefs which structure the microeconomy and give rise to financial markets.
} 
Varela (1991) calls this the "embodied mind" Cognition is mental representation, but representation, which is not "disembodied" but the outcome of a "mindful" activity: mind and body are not separate things.

Weick's ideas lay the foundations of a dynamic view on reality. A dynamic approach on organizations assumes that the actions of its members form and change the environment, which in turn determine actions. A dynamic model supposes that there are feedback loops between individuals in an organization and the environment they create, and which in turn induces change and individual adaptation to handle the change it has created. A dynamic model is grounded in theories and concepts underlying complexity theory. Dynamic models do not pursue stability, nor assume that equilibrium is the most optimal state of a system. Dynamic systems are unpredictable within boundaries and subject to constant feedback mechanisms, which keep it "poised at the edge of chaos". The focus is therefore on trying to understand uncertainty and define concepts how to deal with it. It is neither geared towards controlling, nor predicting.

The question is now, how the general implications of complexity theory and underlying dynamic organization models, affect product innovation and subsequent processes.

\section{Different perspectives on innovation}

Innovation theory and subsequent design of innovation processes have been greatly influenced by traditional organizational theories. Before going into the implications of complexity, some definitions and methodologies will be reviewed.

To start with some definitions of innovation. An innovation or invention usually refers to something new and as such implies that an adaptation is made of the current situation, the old. Innovations can refer to objects, such as a computer or a new car, and in this sense refer to product innovation. Product innovations can either be radical innovations involving a new technology, or more continuous innovations leading to minor improvements or adaptations in the form of a line extension. According to Slappendel (1996) innovation can also refer to the process through which new ideas, objects, and practices are created, developed or reinvented. In its broadest conceptualization an innovation process encompasses periods of design and development, adoption, implementation and diffusion ${ }^{4}$.

From the methodological point of view there are several conceptual models of innovation. Linear models (Utterback, 1994) assume a linear path between the experimentation and idea phase of an innovation, up until the market launch. Linear models are grounded in the traditional paradigm of product innovation, i.e. the so-called Schumpeterian Theory (1961), which assumes that new product outcomes are dependent of the scale of investment and R\&D. Interactive models (van de Ven, 1999) demonstrate that innovation is not a linear process but a collaborative process, where participants are members of a network ruled by the principle of mutual learning. In addition customer focus models

\footnotetext{
${ }^{4}$ Amidon (1998) gives a list of another 10 definitions (www.entovation.com/innovation/10definitions.htm).
} 
(Howells, 1997) focus on "user needs" and evolutionary models (Nelson, 1982) focus on incremental learning processes.

Within this methodological framework, three perspectives on innovation in organizations can be discerned (Slappendel, 1996): (1) the individualist perspective, (2) the structuralist perspective, (3) an interactive process perspective.

An individualist perspective assumes that individuals are a major source of change in organizations. The actions of individuals are not seen to be constrained by external factors, instead individuals are perceived to be self-directing agents who are guided by the individual goals they set. In addition this view holds that individuals are rational and make decisions in order to maximize value or utility.

Whereas the individualist perspective seeks to explain innovative behavior in terms of the characteristics and actions of organizational participants, a structuralist perspective assumes that innovation is determined by organizational characteristics. This line of thought has a deterministic orientation by which organizational behavior is seen to be shaped by impersonal mechanisms that act as external constraints on actors. The approach is to understand these constraining mechanisms by studying the systemic characteristics of organizations which, in turn, are viewed as sub-systems of more inclusive systems, i.e. economy, society.

The interactive process perspective advocated by van de Ven and Dooley (1999) attempts to account for both individual and structural factors through an analysis of their interconnection. Innovation seems to be facilitated by extensive communication between an organization and its environment and the more "open" and willing an organization is to accept and seek out new ideas from its external environment, the more innovative it is 5 .

This last approach takes an integrative stance in trying to explain the relation between organization and customer. The main features of the interactive perspective are:

1. the assumption that innovation is the result of the interaction of structural influences and the actions of individuals;

2. the conceptualization of innovation as a complex process, subject to reinvention and reconfiguration.

In a recent article Chanal (1999) advocates an interactive perspective in a specific combination of a systems- (focusing on information processing) and cognitive (focusing on language and cognitive representations) approach, as a method to study and diagnose innovation processes. The focus can either be from an intra-organizational perspective, or from an inter-organizational perspective. Given the growing importance of the customer and other stakeholders on the business value-chain its seems relevant and appropriate to view innovation in a broader perspective. The approach advocated in this article is to focus on an inter-organizational perspective in a combination of cognitive mapping and social network analysis.

\footnotetext{
${ }^{5}$ Cohen and Levinthal (1990) developed the concept of absorptive capacity to define the capability of an organization to absorb external knowledge and subsequently enlarge the organizational knowledge base.
} 


\section{Innovation as a knowledge creating process}

In a dynamic environment linear models do not seem to explain nor do justice to the complexity of organizations and innovation in its broadest conceptualization. A conventional approach to organizational theory and subsequent strategy formulation based on a focus on traditional production resources, then appears not to be really conducive to long-term competitiveness.

Quinn (1992) developed the concept of the "intelligent organization" based on the argument that organizational strategies in future will depend more on the development and deployment of intellectual resources. Products are regarded as the physical embodiments of the services they deliver. The traditional distinction between a product and a service then becomes irrelevant. More recently, various authors (Weggeman, 1997; Baets, 1998; Davenport and Prusak, 1998) suggest a knowledge-based perspective, in addition to chaos theory (Baets, 1998; Sherman and Schultz, 1998) as a model or paradigm to assess business processes and dynamics.

A knowledge-based perspective looks at innovation from another perspective. According to Wendler and Day (1998) knowledge is an asset unlike any other. The bulk of the cost in knowledge products lies in the creation phase, rather than in manufacturing. Once knowledge has been created, initial development costs can spread across rising volumes. Network effects can emerge as knowledge is shared, and subsequently users can benefit and add value to knowledge as they adapt the knowledge base.

Innovation defined as a continuous knowledge flow amongst individuals within a company, and between individuals and customers, has far-fetching implications for its conceptualization. Traditionally innovation follows from a technological breakthrough or advancement, or developments in the field of R\&D. Since the eighties concepts of branding and customer satisfaction have been added as factors to be taken into account. Changing views on organizations have resulted in a focus on a more people-centered integral business approach. The human resources of a company became the most important asset to be managed and nurtured instead of a cost or liability. The context wherein innovation took place, i.e. the structural elements, came to be seen as a factor that could hinder or add to the success of an innovation trajectory. In addition awareness grew of the growing influence of customers on the business value chain and product innovation. Customer requirements became an important source for innovation.

In the nineties, Nonaka and Takeuchi (1995) wrote their well-known book "The knowledge creating company. How Japanese create the dynamics of economics" and attention shifted to (organizational) knowledge. According to them knowledge is intrinsically related to human beings who own knowledge, combine it in their own mind to form new knowledge, share it, and re-convert it into new knowledge which may eventually lead to the creation of something new or different. Knowledge creation is more than anything a cognitive process based on a learning attitude, and is reflected in social networks.

How does this work, i.e. what is knowledge in essence? A distinction can be made between explicit, tacit and implicit knowledge. Explicit knowledge is knowledge that has been articulated, or expressed while tacit knowledge cannot be articulated. Implicit knowledge has not been articulated yet. It is tacit knowledge, which has the greatest potential business value. Tacit knowledge contains both cognitive and structural aspects. 
On the cognitive level tacit knowledge can be embodied knowledge in people and social networks, and on the structural level tacit knowledge is latent in the embedded processes (routines and procedures) and product created by people.

The embodied knowledge resides at the individual level. People have cognitive models (based on norms, values, and ideas) in their head, which determine how they perceive and represent reality. Knowledge is shared by tapping into the personal experiences of individuals, from which a picture of individual mental models can emerge. By sharing these experiences shared mental models can eventually develop which will form the organizational knowledge repository of a company. Innovation partly results from tapping into the individual experiences and mental models to stimulate individual creativity, but also collective creativity the moment that sharing takes place. If this process, which is essentially a learning process, takes place organization-wide innovation becomes something, which permeates the company.

Knowledge is however also partly implicit. According to Nonaka and Takeuchi (1991) implicit knowledge is converted through interaction between individuals. Taking past experiences as the main focal point of attention has its drawbacks. Past experiences are usually reflected in assumptions underlying a diversity of business processes. These experiences are in their turn then extrapolated to make predictions about the future. Complexity theory assumes that predictability and forecasting are not only not feasible, but also not a realistic way to do business. An alternative way is to approach the organization and its stakeholders as a complex adaptive system.

\section{Innovation: an approach based on complexity}

\subsection{Innovation as a complex system}

As already mentioned earlier, innovation within an organization is usually set up as a series of activities going through different stages and following a sequential path. Not so much from the point of view of the interaction taking place or the relational point of view; but from the perspective of decision making. In essence the set-up is based on a notion that actions of individuals have to be regulated and the process controlled as much as possible in order to reduce uncertainty and unpredictability. Social norms, economic markets, architecture; these are all examples of regulating mechanisms of behavior and interaction.

Innovation organized as a set of activities going through pre-defined stages and review- moments can be understood as a regulatory architecture which influences the behavior of people involved in an innovation process. Innovation defined in this way has an input variable, which can either be driven by technology (technology push), and/or market needs (market pull). When innovation is initiated by market-pull, knowledge about the customer is regarded as an input variable, and customer response as the output variable. The customer is not an integral part of the process.

Depending on the extent to which organizations are defined as "closed" or "open" systems, organizations will continuously transform changing inputs into changing outputs. Innovation is then a complex system because of the intricate relations between its 
members and because understanding of the behavior of the parts does not suffice to explain what is happening at a more general level. How the parts interact together to form a whole is an essential aspect of a complex system. It is exactly because the whole cannot be described without a description of the parts and because each part must be described in relation to other parts, that complexity is created (Simon, 1996). This is what is called "emergent properties". According to Ghatajedaghi (1999) emergent properties are "the property of the whole not the property of the parts, and cannot be deduced from the property of the parts. Emergent properties can hence not be manipulated by analytical tools or do not yield to causal explanation". What he is saying is that emergent properties cannot be measured directly, the only thing one can do is measure their manifestation.

Before going more in depth into the possible implications of complexity on design and process of a product innovation trajectory, the case of a manufacturer in fast moving consumer goods (fmcg) will be reviewed, who now uses a funneled approach for innovation.

\subsection{The case of a fmcg manufacturer}

The company is a big multinational in fast moving consumer goods with a history encompassing more than a century. Under the pressure of market changes the company was forced to merge with a USA based manufacturer, which set as main objective an annual profit growth of $12 \%$. The market wherein this company operates is a mature market, which has been stable for a very long period, but quite recently has been confronted with some "upheaval". Customers are becoming more demanding and less loyal, and more importantly, new players have entered the market changing the rules of the game, and affecting the way business has always been done. Innovation has become more than before a key factor of success, in unison with changing requirements for innovation. While until recently the basis of innovation was a technology driven process initiated by the R\&D department, the environment and players are becoming more and more complex. Not only customer input is becoming of growing importance, but also the ability to integrate that knowledge into the organization. In addition availability of internal knowledge is becoming more and more crucial, as a result of increased internal mobility and need for expert knowledge, which is dispersed.

Wheelwright and Clark (1992) developed an overall "development strategy framework" which was adopted by the company a few years ago. The framework combines three stages of development consisting of: (1) pre-project focal points, (2) projectmanagement and execution and (3) post-project learning and evaluation. The main fundament underlying this framework is the alignment of projects with the overall business strategy.

Besides adopting this framework, parameters were set by the company to measure the success rate of innovations in terms of:

a) speed (fast and responsive development);

b) efficiency (high development productivity) and

c) quality (products with distinction and integration). 
Based on a recent case-study analysis (van der Werf, 1999), two main factors were identified which had an additional effect on the success rate of innovations: the level of involvement and commitment of senior and top management, and the level of integration, cooperation and communication throughout the value chain.

Recently three case studies were carried out of innovation trajectories and some of the additional observations are:

- Development cycles are long;

- Innovation trajectories are R\&D driven, measured by internal standards, and insufficiently driven by customer requirements and customer oriented metrics (customer satisfaction), or knowledge oriented parameters (absorptive capacity);

- Communication amongst project members and between project members and top management is a key factor of success;

- There is lack of clarity how ideas emerge and eventually lead to a certain customer offer.

The observations made are not out of the ordinary. If we look at the rate of failure of innovations (six out of ten), the outcomes support the observations made during the case studies. From an academic point of view, much research has been carried out on innovation. There is however not such a thing as a "unified theory of innovation". There are many studies amongst which the well-known SAPPHO study carried out by SPRU in 1972, which gives insight into the factors influencing successful innovations ${ }^{6}$. Innovation still remains a highly complex and difficult process to manage. This seems to justify the question whether an alternative way of modeling the innovation process, would have a positive effect on its outcome.

\subsection{Innovation as an emergent process}

Summarizing innovation was defined as a complex system and a process of different knowledge flows in which learning and adaptation take place. Innovation in this sense is an iterative process of internal (downward) and external (upward) forces.

In general the building blocks of complex system are formed by the agents who have some characteristics (Bar-Yam, 1997): (1) a performance system, (2) a credit assignment mechanism, (3) a rule discovery mechanism, (4) a mechanism to make predictions. In a nutshell it boils down to how agents interact with their environment, the extent to which they are successful in their interaction, and depending on the degree of success, the interaction patterns that emerge. Strategies that lead to success are pursued and strategies that failed to lead to success are discarded. Actions of agents have purpose, and rules, and patterns underlying these rules, which can be discerned as emergent properties of the same agents.

What are the implications of the above on the prevailing methodological concepts of innovation?

\footnotetext{
${ }^{6}$ Other studies are TNO-STB study, Beckers (1974), Project New Prod Canada, Cooper (1979), Buys Project Industrial Innovation (1984-1987), van de Ven (1999), Minnesota Innovation Research Program.
} 
First of all innovation is regarded as a process of interaction, i.e. focus lies on interaction, which actually takes place at three levels:

a) between individuals and structural elements;

b) amongst individuals within an organization;

c) between individuals of an organization and the external environment.

Second, innovation is seen as being facilitated by extensive communication between an organization and its environment. The more "open" and willing a company is to accept and seek out ideas from the external world, the more tuned it will be to its customers and hence the more innovative. Innovation is a mutually adaptive learning process. In addition innovation is a flow of knowledge among the interacting agents. External knowledge is acquired and subsequently processed in a continuous process of interaction and adaptation. Cognitive schemata and underlying social networks and procedures will be affected by the extent to which knowledge is used and leads to adaptation of behavior and mental models. Knowledge sharing can thus eventually lead to shared representation and collective meaning.

Lastly, the interaction between organization and customer can be regarded as a complex adaptive system. Sherman and Schultz (1998) for one, define complex adaptive systems as follows: "a complex adaptive system (a business, a project team, a network of people) is composed of interacting "agents" (employees, managers, board members, customers, suppliers) following rules (blueprints, values, ethics, laws, economics, organizational or political, friendship, profit maximizing), exchanging influence (goods, ideas, money, trust) with their local and global environments and altering the very environment they are responding to by virtue of "simple" actions."

According to Beinhocker (1997) complex adaptive systems share three key characteristics:

First they are open, dynamic systems. A CAS is always open, and the energy and mass that constantly flow through it keep it in dynamic disequilibrium. The concept of "openness" is very important to understand how complex systems work. "Openness" means that behavior of people within a system can only be understood within the context of their environment. The implication is obvious, namely that everything depends on everything else. This is however not a workable situation, therefore categories of factors need to be defined to determine the boundary of the system and the environment. There are elements that can be controlled, those that cannot be controlled but are fairly predictable and those that can be influenced. The latter for instance encompass customers, suppliers, bosses, and legal networks. Managing a system then becomes more and more managing so-called downward going flows of influence (top down between organization and the environment) and upward going flows of influence (bottom up between the environment and the organization). "Openness" also affects the self-regulatory capacity of the network members. The more "open" the system, the more people will feel free to interact and operate according to their own perception and interpretation of reality.

Second, CAS are made up of interacting agents. The complexity derives from the dynamic interactions of the agents: what each agent does affects one or more agents. The interactions of agents are guided by continuously evolving rules.

Third, CAS exhibit emergence and self-organization. Emergence can be defined as interaction that surfaces out of interaction of a group of people organized in a network, 


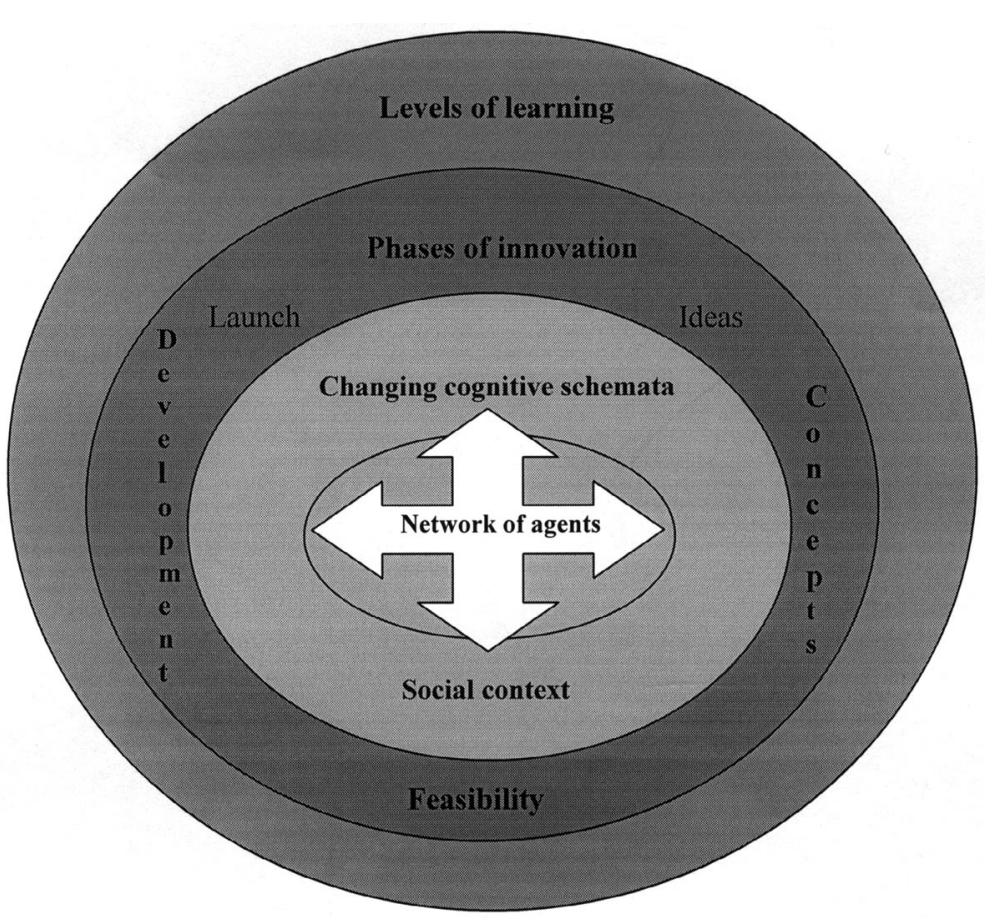

Fig. 1. Product innovation as a complex adaptative system.

whose behavior cannot be predicted or envisioned on the basis of individual, isolated actions. Self-organization occurs when people are free to network with others and pursue their objectives, even if it involves crossing organizational formal structures (Coleman, 1999). The less people are bound by rules and restrictions, the more they will feel "free" to evolve in a direction.

The approach advocated in this paper is to design and assess the innovation process as a complex adaptive system and assume that the system comprises of:

a) a network of agents;

b) different phases of innovation to go through, which manifests itself in different knowledge flows and learning (individual, group, organizational) and

c) different levels of learning, which manifest themselves in the interaction patterns between agents.

The above can be visualized in a multi-layered figure (Fig. 1).

The innovation process is a complex system which continuously evolves and in which the network adapts itself to the changing environment and seeks the optimal fit between its interactions and the changing environment.

What are the implications of the above for an innovation trajectory? The way proposed to design and assess this process, is to follow a step-by step descriptive approach in which via empirical research questions need to be answered, from which a model can eventually be inferred. The questions are related to the different phases in an innovation trajectory (idea, feasibility, concept, development, launch). Whereby the assumption is 
that an innovation process will not be defined in terms of activities or information processes or flows, but in terms of agents, interaction patterns resulting in different levels of learning and continuous adaptation of cognitive schemata and underlying structures.

Interaction is defined as a process of exchange of ideas and knowledge that takes place between people in a specific setting. Learning is in principle aimed at improving and enlarging quality of the individual and organizational knowledge base. Learning can occur at three levels (Argyris and Schon, 1978):

a) Single-loop-learning which occurs when firms detect errors and correct their behavior without altering policies and goals;

b) Double-loop-learning occurs when in addition to detection and correction of errors, existing norms, procedures and policies are questioned;

c) Triple-loop learning occurs when organizations learn how to learn, i.e. improve single-loop and double-loop learning.

Cognitive structures are formed by individual principles, models and rules guiding individual and, eventually, organizational behavior (Sherman and Schultz, 1998). Principles are based on values and norms and the most fundamental to our actions and perception of reality. Models are constructed on the basis of our ideas and principles. Rules are temporary guidelines that define the way we behave in relation to changing conditions and circumstances. Cognition defined in this way is a kind of "mental program" which is partly inherited and partly develops through experience and interaction. Cognitive schemata can be found at the individual and group level. The transition from the one to the other takes place via learning. The interaction between individual/group and context eventually results in models of collective representation and underlying social networks (Madhavan and Grover, 1998). The assumption is that individual cognitive structures together with context form the basis of and define the course and outcome of interaction.

Lewin (1998) propose that to model complex adaptive systems (1) agents' characteristics have to be identified; (2) the relationship amongst agents and (3) the way agents coevolve. The questions that are relevant are:

1. Who are the people responsible and involved in the process of innovation?

2. What are the cognitive schemata of the agents?

3. How are agents connected and how do these connections change over time?

4. What are the pay-off functions and trade-off between agents?

5. How does the system (and subsystems) evolve over time?

The answers to these questions should help model innovation as a complex adaptive system.

\section{Concluding remarks}

This article describes a way to model innovation as a CAS, assuming that this will have a positive effect on innovation performance. Further research will be carried out in the course of three years in which the model will be developed and simulated. Taking people, their cognitive aspects, the context wherein they function and the resulting interaction patterns as a starting point, in first instance a descriptive model will be developed. 
This will form the input for a model of computer simulation. It is only via computer simulation that these complex systems can be represented and its effects visualised. For instance: what happens in a team if timing is not imposed from above, but determined by the group- members themselves, depending on customer feedback? Or, what happens if consumer acceptance tests related to the design of a product are carried out on a continuous basis and alterations have to be implemented? How will the development people tackle this problem? What repercussions will it have on price? What happens if people are completely let free to experiment and develop a product together with customers (with no restrictions on budgets, timing, specifications, material and design?). The simulation should give some answers to these questions and subsequently give insight how to organise and master innovation processes with the ultimate aim to improve their performance.

Innovation trajectories within companies are still largely set up as a series of activities that have to be followed according to a certain path. Whereby customer input is acquired at different stages, but is not a continuous source of input to guide the innovation trajectory. Furthermore objectives are usually pre-defined in terms of profit targets, market share or volume output.

Concepts as one-to-one marketing suppose a growing importance of the role of customers in the business value chain. Customers are however still not integrated as a constant source of valuable knowledge into the organization and especially innovation processes.

Despite all these developments innovation remains one of the most elusive and difficult processes to manage. This article has tried to bring forward an alternative approach to innovation, given the assumption that theories of complexity do more justice to the reality of innovation processes, and hence to the way complexity can be handled and used in a positive way.

What might some of the main implications be of the approach brought forward in this article, for an innovation trajectory, and the relationship with customers?

The design of innovation processes will vary in comparison to what is common practice. Instead of setting innovation up as a series of activities, interaction patterns followed by the members of a network who are functionally connected to each other via formal and informal relations, will be the point of departure. This will be reflected in knowledge flows, which will affect the individual knowledge base, and to the extent that learning takes place, the organizational knowledge base. Innovation then becomes more than anything a process of renewal and adaptation of these knowledge bases.

Innovation is regarded as an "open system" constrained by factors that can be controlled, influenced and, in part, be predicted. The driving motor is the interaction between organizational members and other stakeholders who have something to gain from the product innovation. The outcome will in part measured by tangible aspects, like the physical product. It will however also be measured by the extent to which knowledge is shared, exchanged and gained by the network members.

Order might eventually emerge in a continuous adaptive learning process, coinciding with different innovation phases, which will not follow a sequential path but evolve dynamically. 
The outcome of the process will ultimately depend on the trade off between structural elements and individual interactions, in addition to a trade-off between personal payoff's and the extent to which people feel involved and responsible enough for the group process.

\section{References}

Accounting Management \& Information Technology, 8 (1998).

Anderson P. (1999) Complexity theory and organization science, Organization Science, 10, pp. 216-232.

Argyris C., Schon D.A. (1978) Organizational learning: A theory of action perspective. Addison-Wesley, Reading MA.

Arthur B. (1993) Why do things become more complex, Scientific American, p. 92.

Arthur B. (1994) Positive feedbacks in the economy, McKinsey Quarterly, No. 1, pp. 81-95.

Baets W. (1998) Organizational learning and knowledge technologies in a learning environment. Kluwer Academic Publishers, Dordrecht.

Bar-Yam Y. (1997) Dynamics of complex systems (studies in non-linearity). Addison Wesley, Reading MA.

Beckers W. (1974) STB-TNO study of the distribution between successful and unsuccessful organizations. The Netherlands.

Beinhocker E.D. (1997) Strategy at the edge of chaos, McKinsey Quarterly, No. 1, pp. 24-39.

Boisot M.H. (1995) Information space. A framework for learning in organizations, institutions and culture. Routledge, New York.

Buijs J.A. (1984-1987) Project Industrial Innovation: How to create an innovative company. Delft, The Netherlands.

Chanal V. (1999) Methods for studying innovation processes: Towards a complementarity between organizational and cognitive perspectives, European Journal of Economic and Social Systems, 13, pp. 41-58.

Christensen C.M. (1997) The innovator's dilemma. When new technologies cause great firms to fail. Harvard Business School Press, Boston MA.

Cohen W.M., Levinthal W.A. (1990 Absorptive capacity: a new perspective on learning and innovation, Administrative Science Quaterly, 35, pp. 128-152.

Coleman R. (1999) What enables self-organizing behavior in business, Emergence, 1, pp. 3348.

Cooper R.G. (1979) Project New Prod on the factors correlating to successful new products, Canada.

Cooper R.G. (1987) Winning at new products. Kogan Page, London.

Davenport T., Prusak L. (1998) Working knowledge. How organizations manage what they know. Harvard Business Schools Press, Massachusetts.

Edmonds B. (2000) Capturing social embededness: a constructivist approach. Centre for Policy Modeling, Manchester Metropolitan University.

Ghatajedaghi J. (1999) Systems thinking: Managing complexity and chaos. A platform for designing business architecture. Butterworth Heinemann, London.

Haeckel S.H. (1999) Adaptive enterprise. Creating sense-and-respond organizations. Harvard Business Review Press, Massachusetts. 
Howells J. (1997) Rethinking the market technology relationship of innovation, Research Policy, 3, pp. 1209-1219.

Hultink E.J. (1997) Vier van de tien produkten floppen, Telecommagazine, pp. 47-48.

Kauffman S.A. (1993) The origins of order: Self organization and selection in evolution. Oxford University Press, New York.

Lewin R. (1998) Complexity theory and the organization: Beyond the metaphor, Complexity, 3, pp. 36-40.

Luna F., Stefanson B. (2000) Economic simulations in SWARM: agent-based modeling and object oriented programming. Kluwer Academic Publishers.

Madhavan R., Grover R. (1998) From embedded knowledge to embodied knowledge: New product development as knowledge management, Journal of Marketing, 62, pp. 1-12.

Nelson R., Winter S. (1982) An evolutionary theory of economic change. Harvard Business Review Press, Boston.

Nonaka I. (1991) The knowledge creating company, Harvard Business Review, pp. 96-104.

Nonaka I., Takeuchi H. (1995) The knowledge creating company. How Japanese create the dynamics of economics. Oxford University Press, Oxford.

Pfeffer J., Salancik G. (1978) The external control of organizations. Harper \& Row Publishers, New York.

Porter M.E. (1980) Competitive strategy: Techniques for analyzing industries and competitors. The Free Press, New York.

Quinn J.B. (1992) Intelligent enterprise. A knowledge and service based paradigm for industry. Harvard Business Schools Press, Massachusetts.

Quinn J.B. (1985) Managing innovation: controlled chaos, Harvard Business Review, 3, pp. 73-84.

Slappendel C. (1996) Perspectives on innovation in organizations, Organization studies, No. 17/1, pp. 107-129.

Sherman H., Schultz R. (1998) Open boundaries: Creating business innovation through complexity. Perseus Books, Massachusetts.

Simon H. (1996) The sciences of the artificial. MIT Press, Cambridge MA.

Utterback J.M. (1996) Mastering the dynamics of innovations. Harvard Business School Press, Boston.

Varela F.J. (1991) The embodied mind. Cognitive science and human experience. MIT Press, Massachusetts.

Ven van de A.H., Dooley J. (1999) Explaining organizational dynamics, Organization Science, 10, pp. 358-372.

Weggeman M.C.D.P. (1997) Kennis management: inrichting en besturing von Kennis intensieve organisaties. Scriptum Management, Schiedam.

Wheelwright S., Clark K. (1992) Revolutionizing product development. The Free Press, New York.

Weick K. (1979) The social psychology of organizing. Random House.

Werf v. d. N. (1999) The essence of a successful NPD process. Erasmus University Rotterdam.

Wendler J.C., Day J.D. (1998) Best practice and beyond: knowledge strategies, McKinsey Quarterly, No. 1, pp. 19-25. 